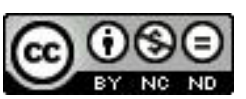

\title{
Escolas Radiofônicas do Rio Grande do Norte: a memória, a narrativa e os retratos da época como uso didático
}

\section{Radiophonic Schools in Rio Grande do Norte: use of memory, narrative and portraits of an era as didactic material}

Márcia Maria Alves de Assis*

\begin{abstract}
Resumo
Neste artigo nos remetemos à nossa pesquisa de mestrado, cujo tema é o ensino de matemática pelo rádio, no Rio Grande do Norte (RN), no período de 1950 a 1970. As Escolas Radiofônicas foram instaladas no RN pela Igreja Católica como forma de levar o ensino formal a comunidades da zona rural. A pesquisa tomou como fontes os arquivos da Arquidiocese de Natal e os depoimentos daqueles que participaram das Escolas Radiofônicas de duas comunidades rurais, Logradouro e Catolé, que hoje fazem parte do município de Lagoa Salgada (RN). Os caminhos da pesquisa nos conduziram a buscar respaldo na História Oral e nos conceitos da História Cultural. Conseguimos evidenciar algumas aplicações do conhecimento matemático estudado nas Escolas Radiofônicas em situações das atividades agrícolas de alunos, como é o caso da cubação da terra. Obtivemos, também, alguns resultados sobre os métodos de ensino e alguns materiais didáticos da época, os quais foram apresentados no produto educacional da pesquisa (em documentário, formatado em DVD).

Palavras-chave: Escolas Radiofônicas. Ensino de Matemática. Rio Grande do Norte. Documentário.

\footnotetext{
* Mestre em Ensino de Ciências Naturais e Matemática pelo Programa de Pós-Graduação em Ensino de Ciências Naturais e Matemática da Universidade Federal do Rio Grande do Norte (PPGECNM UFRN). Doutoranda do Programa de Pós-Graduação em Educação (PPGED - UFRN). Professora Titular do Instituto de Educação Superior Presidente Kennedy, Natal, RN, Brasil. Endereço para correspondência: Rua Guanabara, 145, Neópolis, CEP: 59080-730, Natal, RN, Brasil. E-mail: marciageomat@ig.com.br.
} 


\begin{abstract}
In this article we present our master's degree research, which addresses teaching of mathematics using the radio in the state of Rio Grande do Norte (RN), in the period from 1950 to 1970 . Radiophonic Schools were established in RN by the Catholic church as a way of bringing conventional education to rural areas. Data sources for the research included all the archives the Archdiocese of Natal - RN and testimonies of people who participated in the Radiophonic School in two rural communities, Logradouro and Catolé which today are part of the municipality of Lagoa Salgada (RN). The research led us to seek support in Oral History and concepts of Cultural History. We found evidence of some applications of math knowledge that was studied in the Radiophonic School in situations related to agricultural work of the students, such as measurement of land. We present some findings regarding teaching methods and some textbooks of the time, which were submitted in the educational material produced as a result of the research (in documentary, formatted DVD).
\end{abstract}

Keywords: Radiophonic School. Teaching of Math. State of Rio Grande do Norte (Brazil). Documentary.

\title{
1 Introdução
}

Este artigo trata de um recorte de pesquisa, concluída em 2011, no mestrado profissional do Programa de Pós-Graduação em Ensino de Ciências Naturais e Matemática da Universidade Federal do Rio Grande do Norte, no qual focalizamos nossa atenção para o ensino de Matemática transmitido pelo rádio entre as décadas de 1950 e 1970, pelas Escolas Radiofônicas, período em que grande parte da população brasileira da zona rural não tinha acesso à escola. Assim, as Escolas Radiofônicas cumpriram o papel de levar à zona rural do Estado do Rio Grande do Norte (RN) o ensino a distância para jovens e adultos. Essa foi uma das formas de vencer o analfabetismo, então epidêmico, da população norte-rio-grandense.

Nossas inquietações apontaram para os seguintes questionamentos: quais eram os materiais e métodos de ensino utilizados no Ensino pelo Rádio? Como os monitores ${ }^{1}$ eram treinados para assumir tal função? Como os conteúdos de Matemática eram abordados pelo professor-locutor? Como os alunos desenvolviam suas tarefas nas aulas de Matemática e qual a aplicabilidade desse conhecimento em seu cotidiano?

\footnotetext{
${ }^{1}$ Os Monitores eram professores leigos da comunidade, escolhidos pela Igreja Católica para fazer a mediação das aulas transmitidas pelas Escolas Radiofônicas, ajudando os alunos das comunidades rurais em suas tarefas.
} 
No intuito de responder a esses questionamentos, nossa pesquisa consistiu em compreender alguns aspectos do ensino de Matemática pelas Experiências Radiofônicas. Assim, para o ensino da alfabetização e anos iniciais, nos remetemos às Escolas Radiofônicas de duas comunidades rurais - Logradouro e Catolé que, atualmente, fazem parte do município de Lagoa Salgada² $(\mathrm{RN})$, pois em nossa trajetória de pesquisa encontramos documentos identificando que nessas comunidades foram instaladas duas Escolas Radiofônicas.

No que se refere ao Ensino Ginasial (atual Ensino Fundamental - anos finais), nos detivemos no Curso de Madureza pelo Rádio, pois tivemos acesso integral aos módulos de ensino dessa modalidade, encontrados nos arquivos em que visitamos. Além dos registros escritos disponíveis, nos ancoramos em depoimentos orais. Não houve, entretanto, em momento algum, valoração de uma fonte em detrimento de outra: acreditamos que todas as fontes foram fundamentais para compreendermos o tema que nos propusemos investigar.

Nesse contexto, tivemos como objetivo geral analisar aspectos do percurso histórico do ensino de Matemática pelas Experiências Radiofônicas no Estado do Rio Grande do Norte (RN), entre as décadas de 1950 a 1970, com o intuito de organizar um documentário (CD-ROM) contendo os conteúdos de Matemática estudados pelos que vivenciaram a experiência radiofônica, enfatizando a metodologia de ensino desenvolvida nas aulas. A intenção é que esse documentário possa servir como material de consulta para professores e pesquisadores da área. Nossos objetivos específicos foram:

- Buscar, na literatura específica, por meio da pesquisa bibliográfica, assuntos referentes à história social e política do ensino da Matemática pelo rádio no Estado do Rio Grande do Norte.

- Identificar os recursos didáticos de Matemática e outros materiais utilizados nas Escolas Radiofônicas e Curso de Madureza.

- Identificar o método de aprendizagem e ensino das aulas de Matemática transmitidas pelo rádio.

- Apresentar e analisar o conhecimento matemático mobilizado durante as aulas, buscando compreendê-los no contexto cultural dos alunos das Escolas Radiofônicas.

- Organizar as textualizações das entrevistas realizadas, disponibilizandoas integralmente no estudo.

\footnotetext{
${ }^{2}$ O município de Lagoa Salgada situa-se na mesorregião do Agreste Potiguar, limitando-se com os municípios de Monte Alegre, Vera Cruz, Lagoa de Pedras e Boa Saúde, distante 46 km da capital Natal.
} 
Para a coleta de documentos escritos, visitamos dois arquivos: o arquivo da Rádio Rural de Natal e o arquivo geral da Arquidiocese de Natal. O Arquivo da Diocese de Natal divide-se em dois, a saber: o Arquivo Geral e o arquivo do Serviço de Assistência Rural (SAR). Além desses arquivos, nossos dados foram coletados em acervos pessoais e depoimentos orais.

Para a seleção dos entrevistados, entramos em contato com três técnicas do SAR, as senhoras Maria da Salete Bernardo da Câmara, Dione Violeta de Medeiros e Carol Camy Condon; com dois professores-locutores, João Faustino Ferreira Neto e Maria José Teixeira Peixoto; com duas monitoras, Maria das Dores do Nascimento e Maria Ibanês de França Soares; e com alunos das Escolas Radiofônicas, João Bernardino da Silva Filho, José Bernardino Sobrinho, José Reinaldo da Silva e Maria Ionete de França. Desse modo, foram onze os nossos colaboradores (3 técnicas do SAR, 2 professores-locutores, 2 monitoras e 4 alunos). Todos os colaboradores autorizaram o uso de seus depoimentos, assinando cartas de cessão de direitos disponíveis no relatório da pesquisa.

$\mathrm{Na}$ procura por nossas fontes escritas e depoentes, primeiramente conversamos com o professor João Faustino, que nos informou sobre os arquivos da Arquidiocese de Natal. Ao adentrarmos o arquivo, encontramos documentos com nomes de monitoras e alunos e, a partir desses documentos, chegamos à monitora Maria das Dores do Nascimento, que nos informou sobre Maria Ibanês de França Soares, outra monitora. Essas duas monitoras informaram-nos sobre os alunos, que continuam morando nas mesmas comunidades (Logradouro e Catolé $(\mathrm{RN})$ ) onde estudaram pelas Escolas Radiofônicas. Quanto às três técnicas do SAR e a outra professora-locutora, encontramos duas em um evento sobre as Escolas Radiofônicas, e elas nos levaram às outras duas. A opção por esses depoentes, em parte, se deu pelo denominado critério de rede, segundo o qual, como esclarece Garnica (2006, p. 94), "um colaborador sugere ao pesquisador a pertinência do depoimento de outra pessoa, construindo assim uma rede de colaboradores".

Nas fontes escritas, acessadas nos acervos, encontramos mapas de visitas às escolas da zona rural, relatórios sobre funcionamento das escolas, diários de classe, cartilhas de estudo, módulos de aulas do curso de Madureza (ginasial), fotografias da época, provas de matemática e de outras áreas de conhecimento, scripts de aulas do curso primário, dentre outros. Não encontramos registros orais - gravações originais - de aulas transmitidas pelo rádio.

Como contribuição da pesquisa que realizamos no decorrer do mestrado, sob orientação da professora Dra. Liliane dos Santos Gutierre, nosso produto 
educacional está voltado para a divulgação dessa forma de ensino a distância no que se refere à historiografia do ensino de Matemática do Estado do Rio Grande do Norte (RN), de modo a divulgar a importância de refletirmos sobre os diversos modos de conceber o ensino de Matemática.

Neste artigo descrevemos o referencial teórico-metodológico da pesquisa, a organização e o conteúdo do produto educacional gerado, e fazemos algumas considerações sobre o uso e a divulgação do produto educacional.

\section{Referencial teórico-metodológico}

Como referencial teórico e metodológico de pesquisa, buscamos respaldo nos conceitos da História Cultural, visando à (re)constituição histórica de elementos do meio educacional, principalmente no que diz respeito ao ensino de Matemática e ao Ensino pelo Rádio, e de algumas pessoas que participaram, como atores, desse cenário.

Segundo a concepção de Burke (2004), a História Cultural tem como principal objetivo relatar padrões da cultura, e declara

[...] um interesse pelas práticas narrativas características de uma cultura em particular, as histórias que as pessoas naquela cultura 'contam a si mesmas sobre si mesmas'. 'Tais narrativas culturais', como foram chamadas, oferecem pistas importantes para o mundo em que foram contadas (BURKE, 2004, p. 158).

Para Chartier (1990), a História Cultural é importante para identificar o modo como, em diferentes lugares e momentos, uma realidade social é construída, pensada e difundida. Portanto, ao voltar-se para a vida social, esse campo pode tomar por objeto as formas e os motivos das suas representações e pensá-las como análise do trabalho de representação das classificações e das exclusões que constituem as configurações sociais e conceituais de um tempo ou de um espaço. Chartier (1990) afirma, também, que a História Cultural deve ser entendida como o estudo dos processos com os quais se constrói um sentido, uma vez que as representações podem ser pensadas como "[...] esquemas intelectuais, que criam as figuras graças às quais o presente pode adquirir sentido, o outro tornar-se inteligível e o espaço ser decifrado.” (CHARTIER, 1990, p. 17).

Logo, neste estudo, procuramos interpretar as narrativas dos que 
vivenciaram a Matemática no ensino pelo rádio nas décadas de 1950 a 1970 para compreender aspectos da Matemática estudada nesse contexto.

Buscamos, também, apoio na História Oral, que Thompson (2002, p. 25) afirma ter, como um de seus principais méritos, permitir "em muito maior amplitude do que a maioria das fontes [...] que se recrie a multiplicidade original de pontos de vista".

Ainda, sinaliza Thompson, a História Oral

[...] é uma história construída em torno de pessoas. Ela lança a vida para dentro da própria história e isso alarga seu campo de ação. Admite heróis vindos não só dentre os líderes, mas dentre a maioria desconhecida do povo. Estimula professores e alunos a se tornarem companheiros de trabalho. Traz a história para dentro da comunidade e extrai a história dentro da comunidade. Ajuda aos menos privilegiados, e especialmente os idosos, a conquistar dignidade e autoconfiança. Propicia o contato - e pois, a compreensão - entre classes sociais e entre gerações (THOMPSON, 2002, p. 44).

Para Alberti (2005, p. 155), a História Oral "consiste na realização de entrevistas gravadas com indivíduos que participaram de, ou testemunharam, acontecimentos e conjunturas do passado e do presente." Alberti (2005) afirma, também, que o contexto e os objetivos da pesquisa determinam quais pessoas entrevistar, o que e como perguntar, bem como que destinos serão dados ao material produzido. Em nosso estudo, a História Oral é entendida como metodologia de pesquisa, dando parâmetros para o tratamento das fontes e para a análise dessas fontes.

Nesse sentido, Garnica (2006) situa que a História Oral, enquanto metodologia de pesquisa possui características tão apropriadas para a investigação em Educação Matemática quanto as já utilizadas tradicionalmente. Entendemos que essa metodologia possibilita organizar a busca de traços dos cenários históricos relacionados à formação e às práticas dos docentes e discentes no estado do Rio Grande do Norte (RN), no que se refere ao ensino da Matemática pelo rádio.

As entrevistas que empreendemos foram semi-estruturadas. A entrevista semi-estruturada se caracteriza pela flexibilidade nas perguntas e respostas, de modo que o entrevistador pode acrescentar perguntas, pedir esclarecimentos e complementações. Para valer-se efetivamente dessa flexibilidade, entretanto, o pesquisador deve estar atento para não perder o foco no núcleo central do tema 
em questão e não distrair-se durante a entrevista para que a interlocução possa ocorrer do modo mais fluente possível.

A coleta de documentos escritos nos arquivos foi feita após um estudo bibliográfico inicial acerca do tema, pois, para a composição do material, tanto quanto para a análise documental, é necessário que se conheça a história do documento que está sendo coletado, em quais condições esse documento foi redigido, qual seu propósito e por quem foi feito. Sobre isso, Bacellar (2005, p. 63) afirma: "Contextualizar o documento que se coleta é fundamental para o ofício do historiador." Os documentos, então coletados, foram copiados por meio da fotografia digital, uma opção que se deu em meio a cuidados como os de manuseio e a necessidade de não usar o flash, que podem danificar os materiais.

\section{Produto educacional: o roteiro e o conteúdo}

Neste tópico descrevemos traços da organização e do conteúdo do documentário elaborado como produto educacional, apresentado como parte dos resultados dos trabalhos desenvolvidos. Cumprindo um dos nossos objetivos, organizamos este documentário em CD-ROM, contendo aspectos dos conteúdos de Matemática estudados pelos que vivenciaram a experiência do ensino pelo rádio, enfatizando a metodologia de ensino desenvolvida nas aulas, pretendendo que ele sirva de material de consulta para alunos, professores e pesquisadores da área.

Entendemos o documentário como um recurso audiovisual que pode ter finalidade educativa. De acordo com Paim:

[...] um documentário, um vídeo voltado ao ensino, um desenho animado, um videoclipe, embora utilizem linguagens diferentes, são exemplos de audiovisuais. Audiovisual, portanto, é qualquer trabalho, de ficção ou de documentário, que utilize imagem (geralmente em movimento) e som (locução, diálogo, efeitos sonoros, música e/ou até o silêncio), tendo como suporte a filmagem (16mm, 35mm, super8), a gravação em vídeo (VHS, S-VHS, fita magnética 8mm, Hi-8, Beta-CAM, Beta-MAX, U-Matic, Digital-8, DV, mini-DV e DVCAM) ou ainda a Imagem gerada por computação gráfica (CGI), por meio de programas específicos como Flash, 3D-Max, Maya, After Effects, Premiere, dentre outros. Aliás, todos os programas de computador com interação multimídia são recursos audiovisuais (PAIM, 2006, p. 19). 
Ainda, conforme Paim (2006, p. 19), "um audiovisual que mostra situações sem referencial histórico ou sem embasamento na realidade é considerado ficção". Em nosso caso, o audiovisual proposto busca retratar circunstâncias históricas por meio de investigações e retratar, de algum modo sempre segundo o filtro de quem elabora o documentário, posto ser impossível advogar por uma neutralidade a esse respeito - aspectos de uma iniciativa específica, a do ensino pelo rádio, o que o autor citado considera ser um documentário.

Nessa perspectiva, o nosso objetivo em produzir o documentário fundamenta-se também em Felipe (2006), que trata do recurso audiovisual com fins educacionais:

[...] seja defrontando-se com problemas de natureza epistemológica ou de cunho social, o cinema possibilita que pesquisadores e professores possam explorar seu aparato imagético enquanto tecnologia teórico-conceitual - espaço epistemológico onde um conjunto de técnicas encontra-se com um conjunto de reflexões geradoras de uma gama de conhecimentos que, consequentemente, alimentam uma práxis docente (FELIPE, 2006, p. 111).

Para elaborar a produção do documentário realizamos uma busca a diversos materiais de mesma natureza, avaliando, de cada um, seu formato e intenções, posto que, de início, não tínhamos ideia de como organizar o que seria apresentado. Então, a exemplo de outros documentários, escolhemos fazer uma exposição na qual a pesquisadora opera como apresentadora de cada parte do conteúdo documentado. Há, no início, um texto que situa a audiência sobre a finalidade do documentário, seu tema e intencionalidades, segundo recomendações de Hampe (1997):

[...] na parte inicial do documentário, coloca-se uma breve apresentação do tema, o problema que será tratado, as principais pessoas envolvidas, ou seja, tudo aquilo que o espectador precisa saber para que o documentário avance. Seja breve! Confie na inteligência de seus espectadores e limite essa parte às informações absolutamente essenciais, sem as quais o público não poderia entender o documentário (HAMPE, 1997, p. 3).

Nesse sentido, de modo a fornecer as informações julgadas essenciais, apresentamos textos e a imagem da pesquisadora, intercalados a alguns elementos 
como fotografias de pessoas e lugares, materiais usados nas aulas pelo rádio, citações de referenciais bibliográficos, recortes de documentação e partes de depoimentos orais dos colaboradores.

Para Puccini (2010), a produção de um documentário é composta de três etapas, a pré-produção, a filmagem e a pós-produção. Na primeira etapa, a elaboração da proposta (ou projeto) é muito importante, principalmente se o proponente deseja buscar financiamento para sua execução. Ainda, na etapa da pré-produção, estão a pesquisa, o argumento e o tratamento do conteúdo do documentário que, no nosso caso, sendo o documentário um resultado vinculado à dissertação, foi o pressuposto do qual decorreu o documentário, e não o contrário (como no caso de quem decide elaborar um documentário e fundamenta-se para tal). Partimos, então, para a elaboração do argumento, já que a pesquisa estava concluída e todo o material pesquisado serviu como fonte para a elaboração do roteiro a ser seguido para a composição do documentário.

Considerando que no documentário educacional se faz necessário um bom planejamento dos conteúdos, tendo a tecnologia como aliada em sua divulgação, Franco (1997) aponta que

[...] a tecnologia aliada à técnica tem sempre se colocado à disposição do conteúdo das mensagens. Aquilo que vai ser videografado é objeto de um planejamento e execução preciso e complexo, de modo que a compreensão e a retenção da mensagem por parte do público alvo se realize com um mínimo de esforço. O público, composto de todas as faixas etárias, possui algo em comum: a motivação, o interesse, e sobretudo a curiosidade, todos, como se sabe, elementos primordiais do aprendizado (FRANCO, 1997, p. 21).

Após a etapa do argumento, partimos para o planejamento e apresentação do conteúdo, o que Hampe (1997) denomina de Tratamento. Para isso, deve ocupar o horizonte do elaborador a necessidade de ressaltar

[...] a idéia geral do documentário de forma suficiente para que seja entendido, mas flexível o suficiente para permitir mudanças criativas. O Tratamento é geralmente entendido como um esboço (outline) do documentário. Ele descreve o conteúdo do documentário e o estilo em que ele deve ser filmado. Sobre o que se trata o documentário. O que será incluído. Como será filmado. E como ele se parecerá. Inclui todos os elementos - as pessoas, os lugares, as coisas e os 
eventos - que devem fazer parte do documentário. E mostra como o documentário será organizado (HAMPE, 1997, p. 4).

Desse modo, desse esboço consta, inicialmente, uma breve contextualização sobre a função das Escolas Radiofônicas (Alfabetização e curso Primário), sua época de funcionamento, sua criação, sua estrutura funcional e as principais pessoas envolvidas no sistema radiofônico nas décadas de 1950 e 1960. Em seguida, descrevemos os métodos de ensino e os conteúdos de Matemática mobilizados no contexto das aulas Radiofônicas, no material didático e, segundo os depoimentos coletados, nas práticas de trabalho dos alunos.

A descrição discorre sobre aspectos das Aulas Radiofônicas para a alfabetização e curso primário. Nessas aulas prevalecia o método global, fundamentado numa abordagem analítico-sintética e apoiado em princípios psicológicos e metodológicos com procedimentos que partem do todo, seguindo paulatinamente para a decomposição em partes. Segundo Paiva (2009), esse método não se constituía uma inovação, e era utilizado nas escolas do Ensino Fundamental da rede pública do estado do Rio Grande do Norte. Abordamos, ainda, a estrutura das aulas e dos materiais de ensino de Matemática do Curso de Madureza (Ginasial pelo rádio). Sobre esse nível de ensino, consta do documentário uma tabela com os conteúdos e trechos dos módulos de ensino utilizados nas aulas.

Ressaltamos que todo o conteúdo do documentário foi organizado a partir de documentos escritos, intercalados com os depoimentos orais dos colaboradores da pesquisa. Destacamos os módulos de ensino que foram elaborados pelos professores locutores com base nos livros didáticos da época, que traziam os conteúdos pautados na tendência Formalista Moderna, em que se enfatizava "o uso preciso da linguagem matemática, o rigor e as justificativas das transformações algébricas através das propriedades estruturais." (FIORENTINI, 1995, p. 14).

A parte final do documentário traz algumas considerações sobre as potencialidades e dificuldades dos docentes e discentes em relação aos conteúdos de Matemática desenvolvidos nesses dois níveis de ensino, nessa estratégia de formar pelo rádio, nos reportando aos documentos escritos e aos depoimentos dos colaboradores da pesquisa.

Realizando um diálogo entre fontes orais e escritas, pautados nos pressupostos da História Cultural, podemos afirmar que as fontes escritas nos 
deram evidências sobre os conteúdos de Matemática e sua presença nos documentos da época, e as orais nos forneceram, mais especificamente, pistas sociais e culturais, modos de uso, apropriações.

\section{Considerações didático-pedagógicas sobre o uso e divulgação do documentário}

A proposta de nosso documentário, enquanto ferramenta educativa, consiste em levar ao ambiente de sala de aula alguns aspectos do percurso histórico do ensino de Matemática pelo rádio no estado do Rio Grande do Norte (RN) no período de 1950 a 1970. Para tanto, apresentamos algumas considerações sobre o uso desse produto em sala de aula.

Inicialmente, podemos ressaltar, quanto à mobilização desse documentário em sala de aula, sua potencialidade quanto à discussão de elementos historiográficos. Pesquisadores têm, nele, recursos para pesquisa; professores e estudantes se deparam com a possibilidade de conhecer aspectos da cultura escolar do passado. Em sala de aula, o documentário talvez possa, também, servir de motivação para a discussão de outros temas e conteúdos. Cursos superiores de Pedagogia ou Licenciatura em Matemática podem, a partir do documentário, problematizar práticas pedagógicas, metodologias e conteúdos específicos, segundo uma perspectiva histórica que dê algum sentido ao presente (considerando essas práticas didáticas e pedagógicas como tema precípuo dessas duas instâncias de formação de professores).

Ainda, em relação ao conteúdo histórico, o professor pode explorar o documentário enfatizando os conteúdos abordados no material didático das aulas radiofônicas e sua relação com os conteúdos dos livros didáticos da época e os apresentados atualmente. Quanto aos conteúdos específicos, o professor pode explorar os scripts de aulas das Escolas Radiofônicas, os dos módulos do Curso de Madureza e processos culturais cotidianamente realizados pelos alunos dos antigos cursos radiofônicos, como as estratégias de cubação da terra (relatada no documentário por um dos colaboradores).

Essas potencialidades do documentário dialogam com a afirmação de Mendes (2009):

[...] os professores dos cursos superiores de formação licenciada, certas vezes, esquecem os aspectos sociais e culturais implícitos em cada assunto que abordam nas disciplinas que compõem a grade curricular desses cursos, 
o que implica a dicotomia que se estabelece entre o pensar e o fazer matemática. Ignora-se que esse conhecimento é uma elaboração do intelecto humano, desenvolvido, muitas vezes, a partir da observação do ambiente natural e cultural, manipulação de objetos e situações reais desse ambiente, seguida de tratamento empírico e reflexões sobre tais situações (MENDES, 2009, p. 17).

Já em relação às metodologias de ensino, pode ser debatido em sala de aula o método global usado nas Escolas Radiofônicas, relatado no documentário por meio de documentos e explicado no depoimento de uma professora-locutora. Podem, também, ser exploradas, de modo problematizador, tendências didáticas para o ensino de Matemática indicadas por Fiorentini (1995), como a Empírico Ativista (exemplificada, no documentário, a partir de uma prova do curso primário e comentada pela pesquisadora) e a Formalista Moderna (identificadas em alguns módulos do curso de Madureza). Por fim, alguns aspectos da modalidade da educação a distância pelo rádio, bem como o acesso atual a outras tecnologias podem ser discutidos em sala de aula, questionando de que forma essa modalidade de ensino tem influenciado o ensino e a aprendizagem de Matemática e quais as perspectivas futuras.

Em relação à divulgação da pesquisa, no período de 2009 a 2011, vários foram os textos apresentados em eventos ${ }^{3}$ e revistas como a Revista da Matemática, Ensino e Cultura - REMATEC ${ }^{4}$, da UFRN, e a revista eletrônica EM TEIA ${ }^{5}$. A versão integral da dissertação (ASSIS, 2011) e do documentário

\footnotetext{
${ }^{3}$ ASSIS, M. M. A. de; GUTIERRE, L. dos S. A Matemática e o Rádio: depoimentos orais de monitoras e alunos. In: COLÓQUIO DE HISTÓRIA E TECNOLOGIA NO ENSINO DA MATEMÁTICA, 5., 2010, Recife. Anais... Recife: Universidade Federal de Pernambuco, 2010. p.1-7; ASSIS, M. M. A. de; GUTIERRE, L. dos S. As Escolas Radiofônicas e o Ensino de Matemática no RN. In: ENCONTRO NACIONAL DE EDUCAÇÃO MATEMÁTICA, 10., 2010, Salvador. Anais... Salvador: Universidade Federal da Bahia/SBEM, 2010. p. 1-10; ASSIS, M. M. A. de; GUTIERRE, L. dos S. Matemática: algumas considerações sobre o ensino das escolas radiofônicas/RN. In: CONFERÊNCIA INTERAMERICANA DE EDUCAÇÃO MATEMÁTICA, 13., 2011, Recife. Anais... Recife: Universidade Federal de Pernambuco, 2011. p. 1-8; ASSIS, M. M. A. de; GUTIERRE, L. dos S.. Influência do Ensino de Matemática nas Práticas Diárias de Alunos das Escolas Radiofônicas do RN. In: ENCONTRO REGIONAL DE EDUCAÇÃO MATEMÁTICA, 2., 2011, Mossoró. Anais... Universidade Estadual do Rio Grande do Norte/SBEM/RN, 2011. p. 1-10; ASSIS, M. M. A. de; GUTIERRE, L. dos S. A Matemática em Atividades Agrícolas: o que dizem os alunos das escolas radiofônicas de Lagoa Salgada/RN (1950 - 1970). In: SEMANA DA MATEMÁTICA DA UFRN, 23., 2011, Natal. Anais... Natal: Universidade Federal do Rio Grande do Norte, 2011. p. 1-8.

${ }^{4}$ ASSIS, M. M. A. de. O ensino de Matemática através do rádio: Entrevista com o professor João Faustino Ferreira Neto. REMATEC - Revista de Matemática, Ensino e Cultura, Natal, ano 4, n. 5, p. 9-12, jul. 2009.

${ }^{5}$ ASSIS, M. M. A. de; MACIEL, L. S. K. R. As Escolas Radiofônicas e o Ensino de Matemática: um estudo histórico. EM TEIA - Revista de Educação Matemática e Tecnologia Iberoamericana, Recife/ PE, v. 2, n. 2, p. 1-15, 2011.
} 
encontram-se no site do programa de Pós-graduação em Ciências Naturais e Matemática da UFRN (http://www.posgraduacao.ufrn.br/ppgecnm), na biblioteca do CCET/UFRN, na biblioteca do Instituto Kennedy (IFESP) - Natal (RN), no ambiente virtual de aprendizagem do Instituto Kennedy <http://www.ifesp.edu.br/ ead> e na Secretaria de Educação da cidade de Lagoa Salgada (RN). O documentário está disponível (dividido em duas partes) nos links: (parte 1)<https:/ /www.youtube.com/watch?v=dprEMGvXJ7g> e (parte 2) <https:// www.youtube.com/watch?v=9tiltP81Ozs $>$.

\section{Referências}

ALBERTI, V. Histórias dentro da história. In: PINSKY, C. B. et al. (Org.). Fontes históricas. São Paulo: Contexto, 2005. p. 155-202.

ASSIS, M. M. A. de. Ensino de matemática pelo rádio (1950 - 1970): uma história falada de um documentário didático / Márcia Maria Alves de Assis. 2011. 173f. Dissertação (Mestrado em Ensino de Matemática) - Universidade Federal do Rio Grande do Norte, Natal, 2011.

BACELLAR, C. Uso e mau uso dos arquivos. In: PINSKY, C. B. et al. (Org.). Fontes históricas. São Paulo: Contexto, 2005. p. 23-76.

BURKE, P. O que é história cultural? Tradução de Sérgio Goes de Paula. Rio de Janeiro: Jorge Zahar Ed., 2004.

CHARTIER, R. A História Cultural: entre práticas e representações. Tradução de Maria Manuela Galhardo. Rio de Janeiro: Bertrand Brasil, 1990.

FELIPE, M. A. Cinema e Educação: interfaces, conceitos e práticas docentes. 2006. 204f. Tese (Doutorado em Educação) - Universidade Federal do Rio Grande do Norte, Natal, 2006.

FIORENTINI, D. Alguns modos de ver e conceber o ensino da matemática no Brasil. Zetetiké, Campinas, v. 3, n. 4, p. 1-37, nov. 1995.

FRANCO, G. A. L. O Vídeo Educativo: subsídios para a leitura crítica de documentários. Tecnologia Educacional, Rio de Janeiro, n. 136/137, p. 20-23, maio/ago. 1997.

GARNICA, A. V. M. História Oral e Educação Matemática. In: BORBA, M. C.; ARAÚJO, J. L. (Org.). Pesquisa Qualitativa em Educação Matemática. 2. ed. Belo Horizonte: Autêntica, 2006. p. 79-100. 
HAMPE, B. Escrevendo um documentário. NUPPAG - Núcleo de Pesquisa e Produção Audiovisual em Geografia - IGCE-UNESP/Rio Claro, 1997. Disponível em: $<$ http://www.slideshare.net/faellator/escrevendo-um-documentario $>$. Acesso em: 18 set. 2011.

MENDES, I. A. Matemática e investigação em sala de aula: tecendo redes cognitivas na aprendizagem. São Paulo: Editora Livraria da Física, 2009.

PAIM, P. G. A história da borracha na Amazônia e a química orgânica: produção de um vídeo didático-educativo para o ensino médio. 2006. 129f. Dissertação (Mestrado em Ensino de Ciência) - Universidade de Brasília, Brasília/DF, 2006.

PAIVA, M. M. de. (Org.). Escolas Radiofônicas de Natal: uma história construída por muitos (1959 - 1966). Brasília: Liber Livro Editora, 2009.

PUCCINI, S. Roteiro de documentário: da pré-produção à pós-produção. 2. ed. Campinas: Papirus, 2010.

THOMPSON, P. A voz do passado: história oral. Tradução de Lólio Lourenço de Oliveira. Rio de Janeiro: Paz e Terra, 2002. 